\title{
QUALITY OF LAYING HEN EGGS DURING STORAGE DEPENDING ON EGG WEIGHT AND TYPE OF CAGE SYSTEM (CONVENTIONAL VS. FURNISHED CAGES)*
}

\author{
Justyna Batkowska`, Antoni Brodacki, Sebastian Knaga \\ Department of Biological Basis of Animal Production, University of Life Sciences in Lublin, \\ Akademicka 13, 20-950 Lublin, Poland \\ •Corresponding author: justyna.batkowska@up.lublin.pl
}

\begin{abstract}
The aim of the study was to demonstrate the relationship of egg weight and egg quality traits with storage time and type of cages in which the laying hens were kept. The material consisted of 960 eggs from same age Hy-Line Brown hens kept in conventional and furnished cages at the same time in one building. The eggs were randomly collected, sorted by weight (S, M, L and XL), and stored under controlled temperature and humidity conditions. All eggs were weighed on days 1 (day of laying) and 28 of the experiment. During the same time they were candled to determine depth of the air cell, and 60 eggs from each subgroup were chosen to evaluate quality traits (egg weight and egg specific gravity), shell characteristics (shell strength, weight, thickness and density), and interior quality of eggs (albumen height and pH, yolk colour, weight and pH). The eggs (especially those from the heavier weight classes, $\mathrm{XL}$ and $\mathrm{L}$ ) from hens reared in furnished cages were characterized by significantly smaller quality changes (egg weight loss, yolk proportion, albumen height, Haugh units) due to storage time in relation to those from hens kept in conventional cages. This fact could point to their better suitability for consumption. In addition to the housing system, changes occurring in eggs during storage should also be considered in terms of their weight class. Economically important egg traits (e.g. egg weight, shell strength) were better in eggs from furnished compared to conventional cages.
\end{abstract}

Key words: battery cages, furnished cages, egg storage, egg quality

Hen egg quality is affected by many factors including bird genotype and age (Krawczyk, 2009; Zita et al., 2009; Sarica et al., 2012), environmental conditions (Hester, 2005), feed additives (Safaa et al., 2008) and rearing system (Đjukić-Stojčić et al., 2009; Ferrante et al., 2009; Tůmová et al., 2009). Farms in which table eggs are produced, are usually equipped with automated, battery-operated housing systems. The EU Directive 1999/74, which came into effect on 1 January 2012, sets the mini-

\footnotetext{
* Work financed from research project No. ZKB/U-29.
} 
mum standards for the protection of laying hens and introduces new parameters of cages for these birds. Under the new regulations, hens should have access to perches, dust baths and nests, and should be provided with more space than in conventional cages. The need to change cage equipment caused a reduction in bird density while decreasing the number of eggs produced.

A number of studies reported that furnished cages considerably improved the welfare of hens (Pohle and Cheng, 2009) and the hygiene of eggs (Roll et al., 2009), which do not differ in weight (Tactacan et al., 2009) and have better shell quality compared to eggs from birds which were kept in conventional cages (Karkulín, $2006 \mathrm{~b}$ ). The range and diversity of changes that can occur in egg quality traits during 28 days of storage (Commission Regulation (EC) No 589/2008) are influenced by the time and microclimatic conditions associated with the housing system of hens (Gavril and Usturoi, 2011; Jin et al., 2011).

Changes due to storage occur in eggs regardless of the hen housing system. They are mainly reflected in a reduction of egg weight due to water loss. At the same time, the increase in yolk and shell percentage occurs because water loss is mostly related to albumen. These changes are already visible after 24 hours of egg storage (Scott and Silversides, 2000). During storage the values of traits such as albumen height, yolk height and Haugh units are observed to change, while shell thickness remains unchanged (Tabidi, 2011). Storage of eggs in the refrigerator can reduce the strength of the shell and yolk vitelline membrane (Jones, 2005).

The aim of the study was to demonstrate the differences in hen egg weight and quality traits as influenced by storage time and type of cages in which hens were kept.

\section{Material and methods}

The material consisted of eggs obtained from Hy-Line Brown hens at the same time of the day at 33 weeks of age. The birds were kept in the same building equipped with two types of cages (conventional or furnished) in compact tier batteries, under microclimate conditions complying with laying hen farm standards. The stocking density of hens was consistent with the standards for implementation period (550 $\mathrm{cm}^{2} /$ hen, 5-6 birds per cage). Bird density in furnished cages was about $26 \%$ lower than in conventional cages $\left(750 \mathrm{~cm}^{2} /\right.$ hen, 7 birds per cage); additionally, furnished cages were equipped with a nest (made of artificial grass mat), dust bath area (filled with grit), perches (15 cm per hen), claw-shortening devices and met the requirements specified in EU Directive 1999/74. All birds were fed with the same commercial complete diet for laying hens according to the age and laying phase of the hens (ME 11.6MJ, protein 17.0\%, fibre 3.9\%, Ca 3.8\%, P 0.55\%). Eggs were randomly collected from the total number of eggs laid on that day by hens kept in conventional and furnished cages (about 9000 eggs from each type of cage). They were sorted by weight (S, M, L, XL; in accordance with Commission Regulation (EC) No 589/2008), individually numbered, placed on cardboard trays by 30 units, and stored under controlled temperature $\left(15-18^{\circ} \mathrm{C}\right)$ and humidity $(50-70 \%)$ conditions. 
All eggs were weighed on the day of laying (day 1) and on day 28 of the experiment. At the same time they were candled to determine the depth of the air cell using measuring gauge. Egg weight loss was expressed as percentage change in final egg weight in relation to initial weight. On days 1 (day of laying) and 28, 60 eggs were chosen from each weight subgroup for egg quality evaluation, and a total of 960 eggs were analysed (Table 1). The EQM system (Egg Quality Measurements by TSS) and Instron Mini 55 apparatus were used. The following traits were evaluated: egg weight, egg specific gravity (calculated on the basis of egg weight measured in air and in water, Archimedes' principle), and characteristics of shell (strength, weight, thickness and density calculated on the basis of egg weight and shell area), albumen (height and $\mathrm{pH}$ ), and yolk (colour, weight and $\mathrm{pH}$ ). The $\mathrm{pH}$ values were determined using pH meter CP-251 (PN-ISO 2917:2001).

Table 1. The number of eggs subjected to quality traits evaluation depending on the egg weight class, storage time and cage housing system

\begin{tabular}{|c|c|c|c|c|c|c|c|c|c|c|}
\hline & & \multicolumn{8}{|c|}{ Egg weight class } & \multirow{3}{*}{ Total } \\
\hline & & \multicolumn{2}{|c|}{ XL } & \multicolumn{2}{|c|}{$\mathrm{L}$} & \multicolumn{2}{|c|}{ M } & \multicolumn{2}{|c|}{ S } & \\
\hline \multicolumn{2}{|c|}{ Cage type } & Con & Fur & Con & Fur & Con & Fur & Con & Fur & \\
\hline \multirow[t]{3}{*}{ Time } & 1 & 60 & 60 & 60 & 60 & 60 & 60 & 60 & 60 & 480 \\
\hline & 28 & 60 & 60 & 60 & 60 & 60 & 60 & 60 & 60 & 480 \\
\hline & total & 120 & 120 & 120 & 120 & 120 & 120 & 120 & 120 & 960 \\
\hline
\end{tabular}

Con - conventional cages; Fur - furnished cages.

The data were analysed with the use of statistical package SPSS ver. 21.0 (IBM, 2011). The normality of data was verified using Kolmogorov-Smirnov test. The multifactoral analysis of variance with Duncan's post-hoc test was carried out. The statistical model incorporated all the analysed factors such as storage time (T), type of cage for laying hens (C) and egg weight (EW), as well as interactions between these factors.

\section{Results}

Table 2 presents the changes in egg weight during the experiment. Egg weight was considerably affected by storage time and weight class. XL and S class eggs from layers kept in furnished cages were characterised by significantly smaller weight loss during 28 days of storage than eggs from hens kept in conventional cages. At the same time the highest total percentage weight loss was noticed in smallest eggs (S class). The depth of the air cell was significantly influenced by all the analysed factors, such as storage time, weight grading and cage type. At the beginning of the experiment the air cell was not visible, regardless of the experimental subgroup. After 28 days of the study deeper air cell was observed in larger compared to smaller eggs, and in eggs from conventional compared to furnished cages. This parameter was also considerably affected by all types of analysed interactions between experimental factors. 


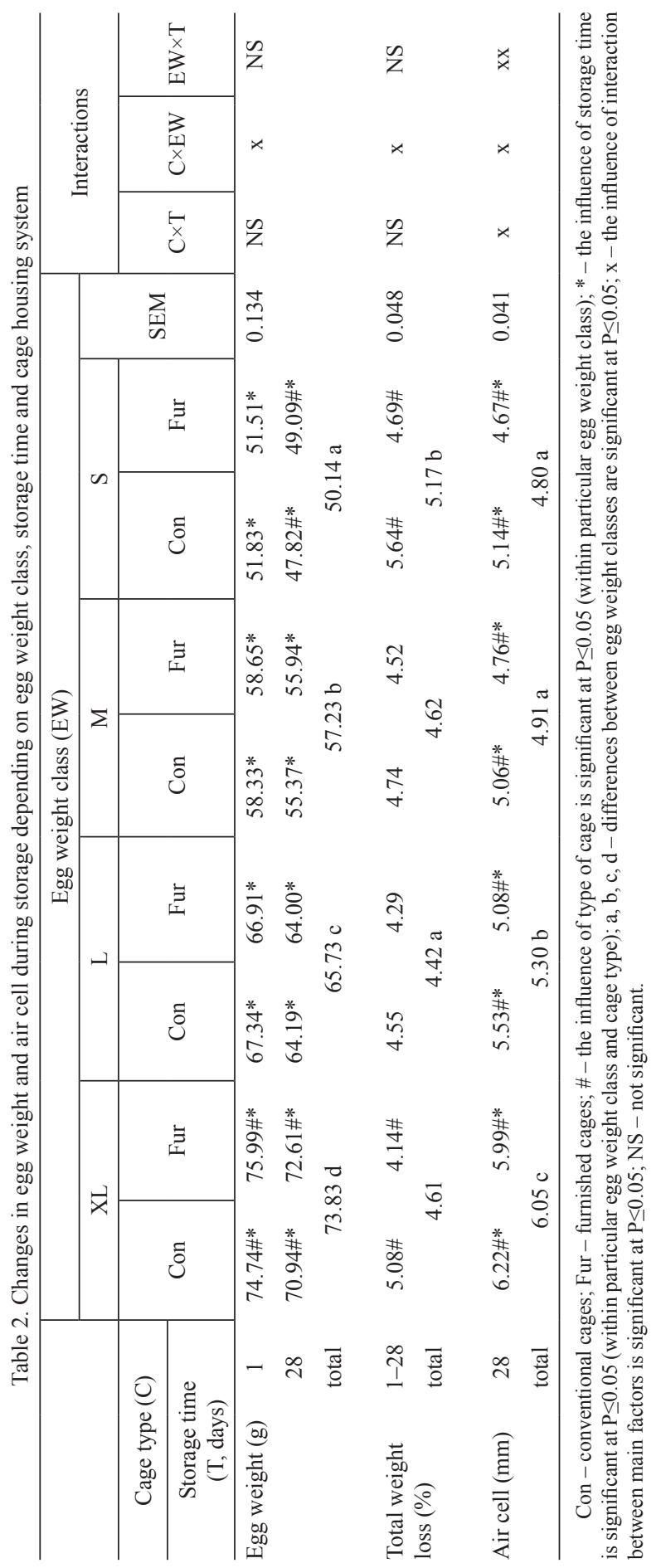




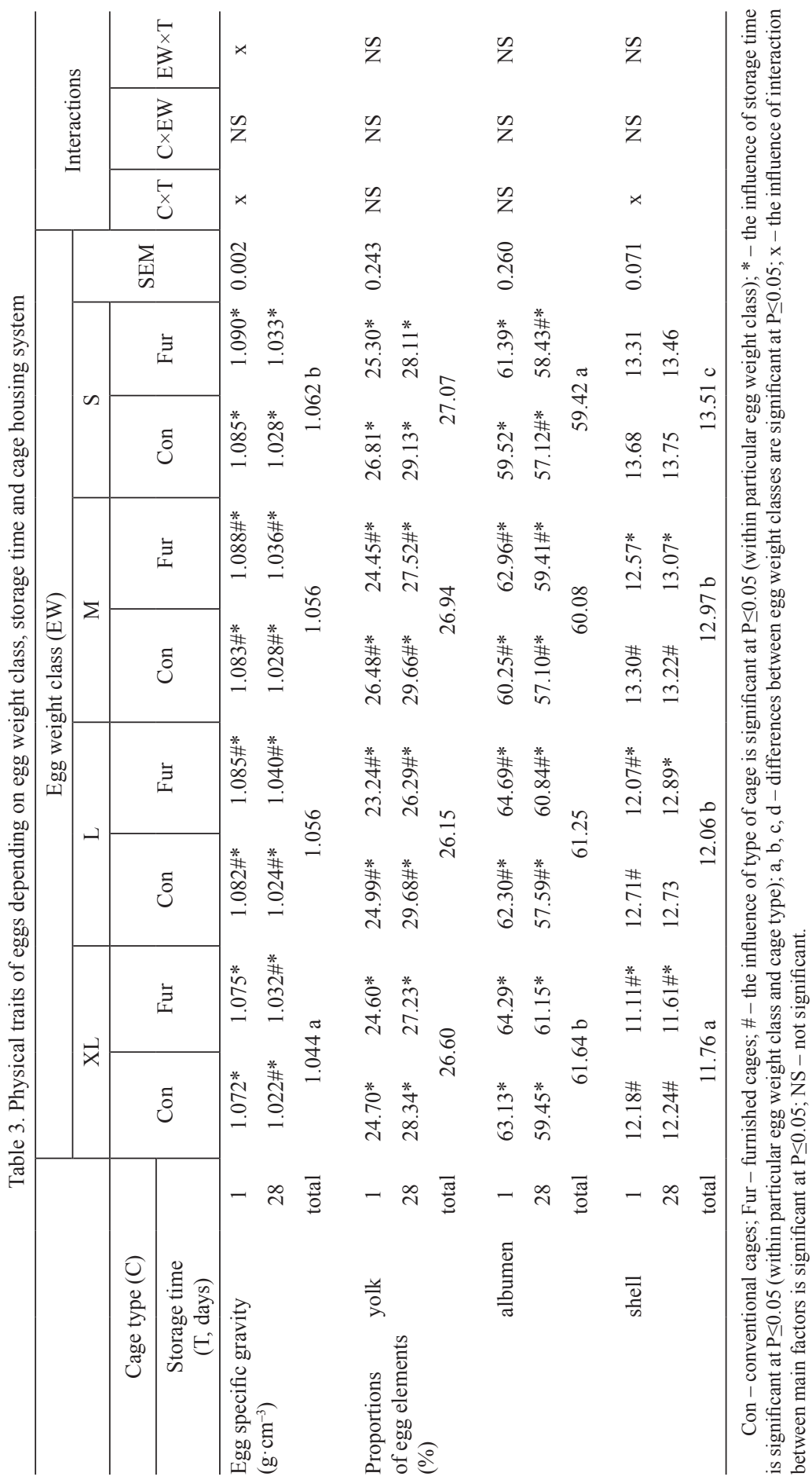




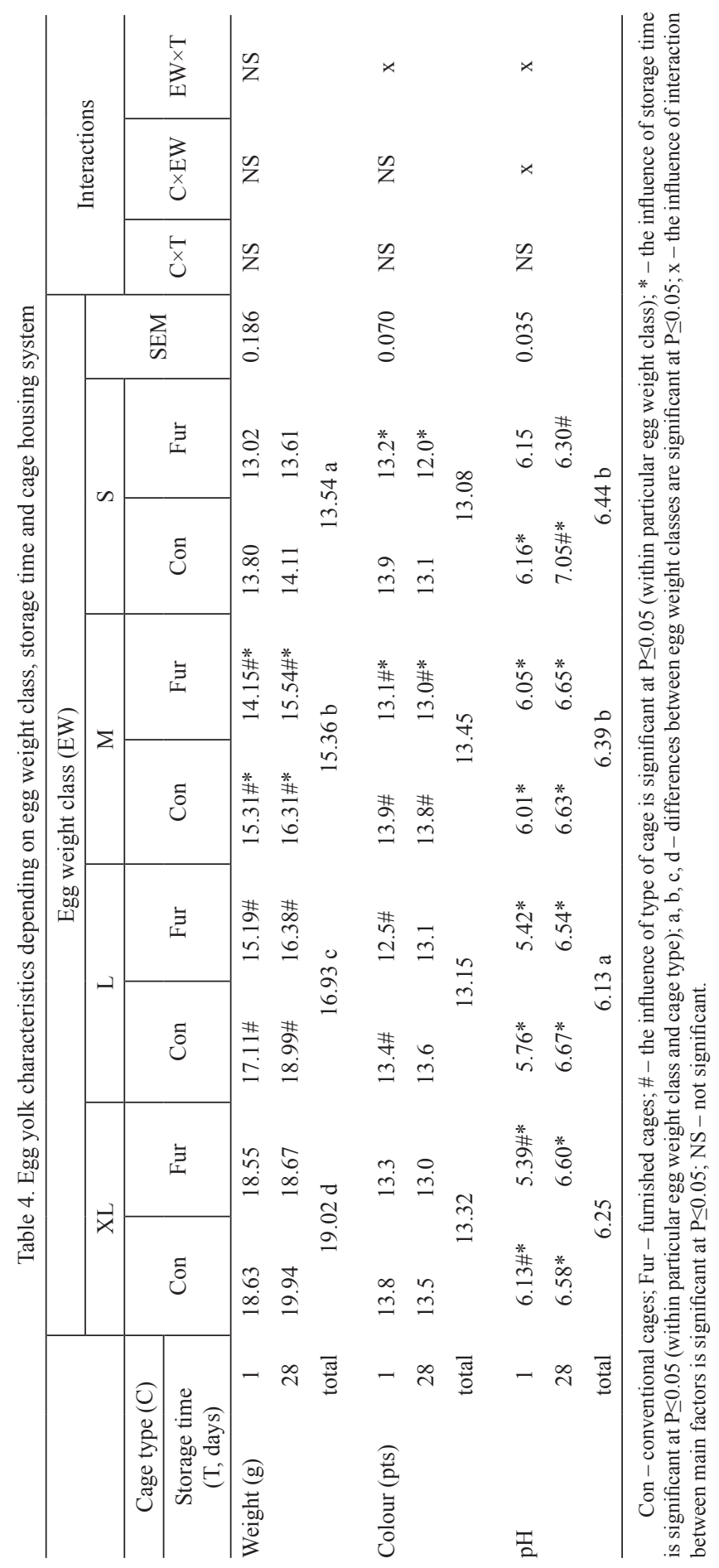




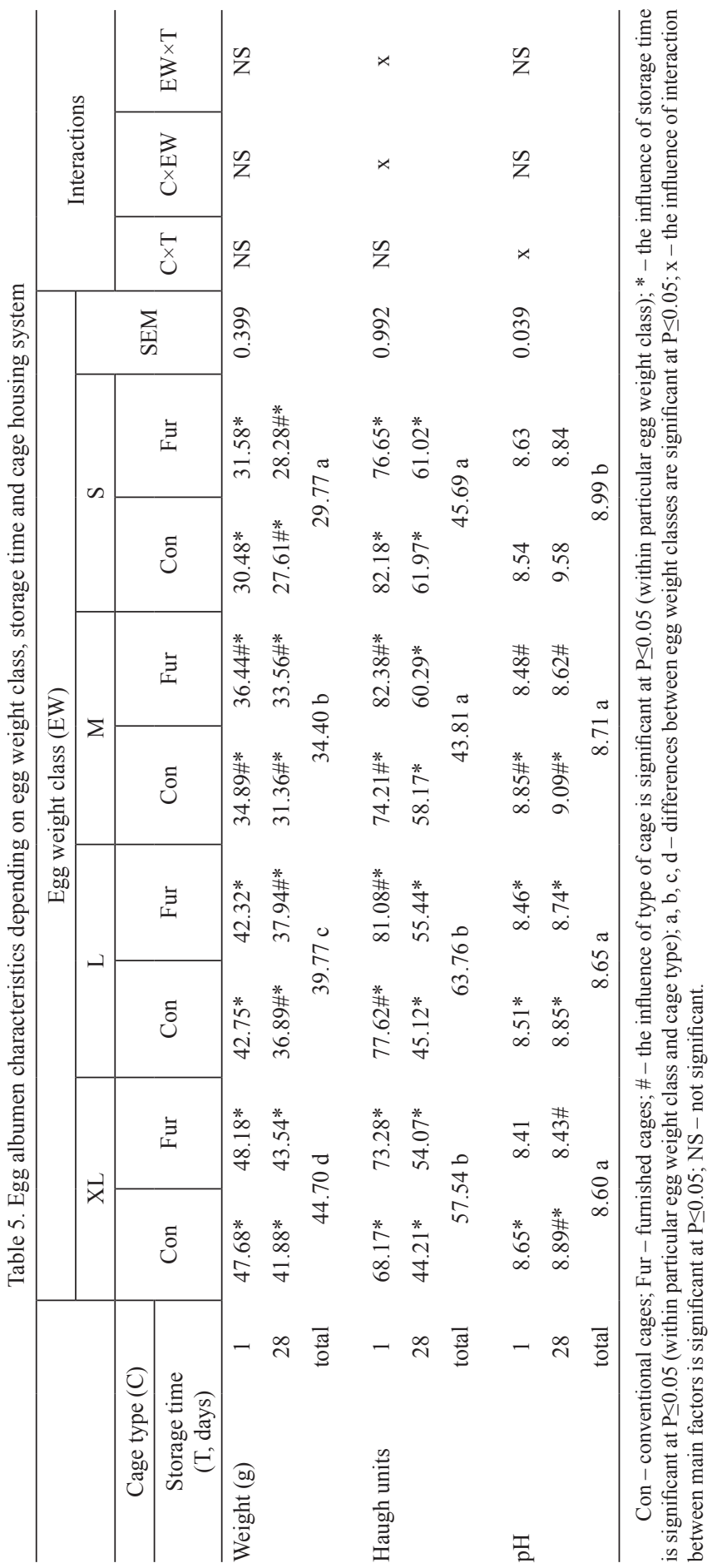




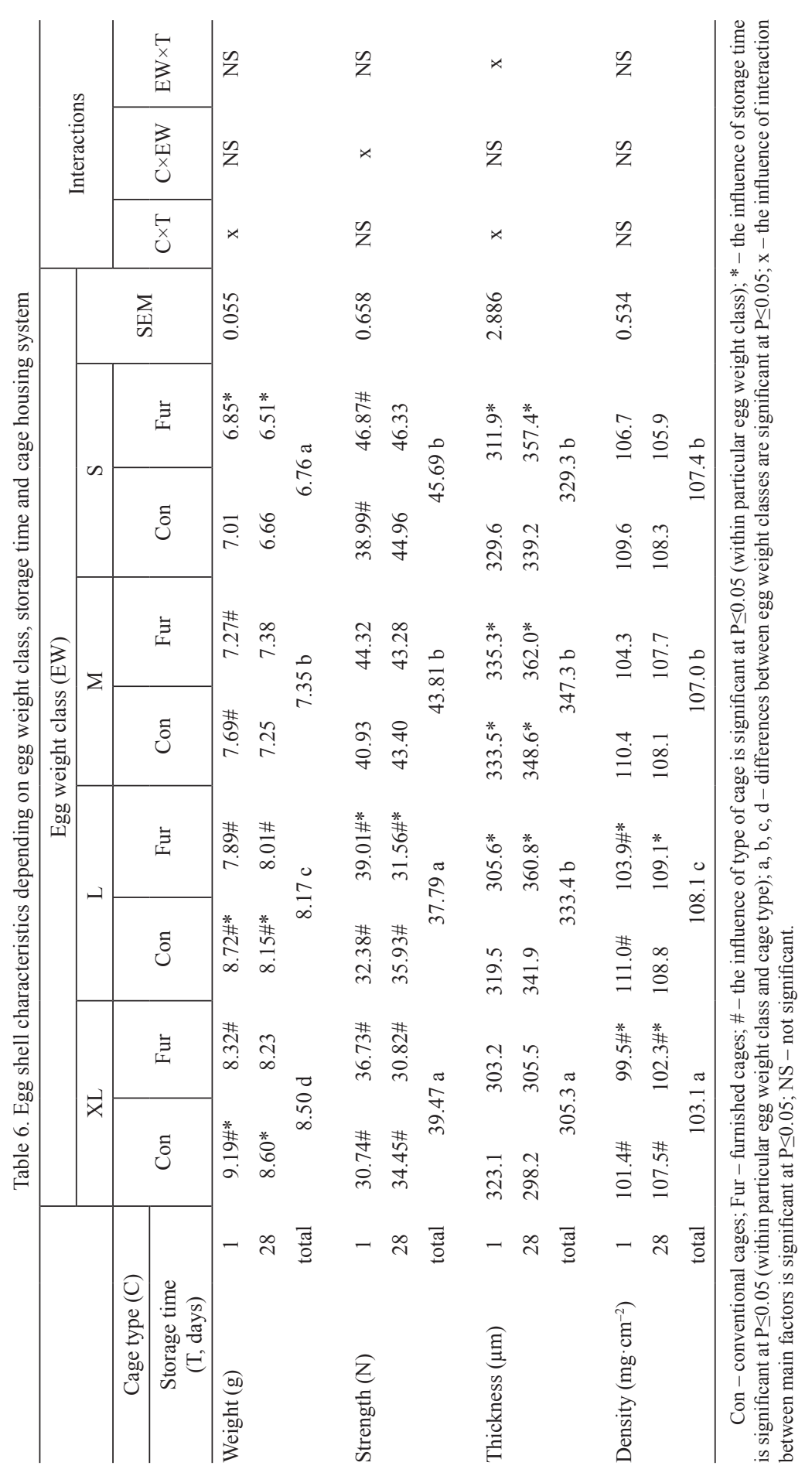


Table 3 shows the specific gravity and proportions of morphological elements in eggs according to storage time, cage type and egg weight. Both egg weight and egg specific gravity depended on all experimental factors. In all the analysed subgroups the value of this trait decreased significantly during 28 days of storage. At the same time it was noted that after the experiment higher specific gravity was characteristic of the eggs from hens kept in furnished compared to conventional cages, except $\mathrm{S}$ weight class, where the difference was not significant. Cage type also influenced the proportions of morphological elements in eggs, especially in L and M classes. Eggs from hens kept in furnished cages were characterised by smaller percentage of yolk and shell and higher percentage of albumen compared to the corresponding subgroups in conventional cages. According to the rule that heavier eggs contain more albumen than lighter eggs, the rise of egg weight was paralleled by an increase in albumen percentage and a decrease in yolk and shell percentage. The duration of experiment was an important factor which caused differences in the proportion of yolk and albumen in all analysed subgroups of eggs. The content of yolk significantly increased and albumen decreased as time passed. However, the values of these indicators were affected by the main experimental factors, not by their interactions.

Table 4 shows the egg yolk traits according to experimental factors. While storage time created differences in the proportion of yolk in egg mass, it had only slight impact on yolk weight (M class). However, this trait was significantly affected by egg weight and the type of cage for laying hens, especially in L and M classes of eggs. Yolks in eggs from conventional cages as well as yolks in larger eggs were heavier. Eggs from furnished cages were characterised by less intensive yolk colour in L (day 1) and $\mathrm{M}$ class. In M class this trait changed considerably during storage. Yolk pH ranged from 5.39 to 6.16 at the beginning of the experiment, and changed significantly during storage. The values of $\mathrm{pH}$ increased from $2.4 \%$ to as much as $23.6 \%$. In the case of eggs from hens kept in furnished cages there were fairly regular changes in the level of this parameter in particular weight classes, i.e. the highest yolk pH increase was found in XL class, but the changes in consecutive weight classes were lower. In the case of $\mathrm{pH}$ the influence of $\mathrm{C} \times \mathrm{EW}$ and $\mathrm{EW} \times \mathrm{T}$ interactions was statistically significant.

The analysed traits of egg albumen are presented in Table 5. In all subgroups albumen weight loss was about $10 \%$ of its initial weight. Simultaneously, higher albumen weight was characteristic of the eggs in which higher initial weight was previously noticed as well as of the eggs from laying hens kept in furnished cages. Weight loss due to storage time was also smaller for eggs from furnished cages. Haugh units were affected by egg weight; they were higher for eggs from furnished compared to conventional cages (eggs from L and M classes) and also decreased significantly during storage. However, it should be noted that at the end of the experiment albumen quality allowed the eggs to be ranked according to their weight from $\mathrm{S}$ (best quality) to XL, regardless of cage type. Similarly as in yolk, $\mathrm{pH}$ was also noticed to increase in albumen during storage. Lower values of the traits were recorded in eggs from hens kept in furnished cages. The albumen weight was affected only by the main factors such as type of cage and egg weight. However, Haugh units were considerably influenced by the interaction between these factors and the interaction between egg 
weight and storage time. In the case of albumen $\mathrm{pH}$ interaction between storage time and type of cage was statistically significant. These parameters changed also under the influence of the main factors (cage type, egg weight).

Table 6 contains the results of shell quality traits evaluation for the eggs studied. Basically, shell weight depended on egg weight; it was lower in small eggs (except $M$ class eggs) and in eggs from furnished compared to conventional cages. A similar influence of cage type was found for shell strength. The thickness of shell was also under the influence of egg weight, and in eggs from laying hens kept in furnished cages values of this trait increased during storage. Shell density in eggs from conventional cages was similar at the beginning and at the end of the study. Also higher density was characteristic of lighter eggs, regardless of cage type, during the first analysis. At the end of the experiment the differences between egg weight classes were less pronounced. The interaction between the main factors was not statistically confirmed.

\section{Discussion}

Tabidi (2011) noticed that storage time caused significant differences in traits such as egg weight, albumen height and Haugh units. The shape index and shell thickness remained unchanged. However, weight loss just after 21 days of storage was higher than 5\%. Additionally, they did not show a statistically significant impact of storage time as well as its interaction with housing system on the egg weight loss. In our study the weight loss even after 28 days was smaller but significant, in relation to the cited paper. Also it was about one-thirds smaller than the values recorded by Şekeroğlu et al. (2008) during 20 days of storage despite the use of lower temperature range $\left(8^{\circ} \mathrm{C}\right)$ by these authors. Compared to our study, also much higher weight loss of about $7 \%$ after 28 days of storage was found in eggs from caged hens by Trziszka et al. (2004).

Considering the impact of housing system (free range, deep litter) and storage time on table egg quality, it was stated that only yolk colour was influenced by hen housing method (Şekeroğlu et al., 2008). The storage time caused changes in such quality parameters as egg specific gravity, $\mathrm{pH}$, albumen height and index, Haugh units, and yolk index and colour. The interaction between those two factors was significant only for yolk colour. In our study the impact of storage time as well as cage type on all yolk and albumen traits was indicated. We also noticed significant interaction between these factors for traits such as egg specific gravity or shell thickness. Menezes et al. (2012) suggested that bird density rather than the cage housing system is the factor influencing egg quality. They analysed Haugh units as an indicator of egg quality during the storage. It was stated that eggs from hens kept in smaller groups (625 vs. $500 \mathrm{~cm}^{2}$ per bird) were characterised by higher values of this parameter, especially in older birds (45-50 weeks of age). We also confirmed higher Haugh units for eggs from furnished cages ( $\mathrm{L}$ and $\mathrm{M}$ classes), in which hens were stocked at lower density. 
When evaluating the quality of eggs from conventional and furnished cages, Valkonen et al. (2008) noticed the differentiation caused by this factor at 36 weeks of age and only in the egg specific gravity and yolk weight. In another research (Jin et al., 2011) statistically significant shell weight loss during storage was shown, but a downward trend was also stated for shell percentage in egg mass. The changes observed in our study were consistent in the case of shell weight, but inverse in the case of shell percentage in egg weight. Karkulín (2006 a), who passed over the storage time as the experimental factor, demonstrated that hens housed in enriched cages laid considerably heavier eggs compared to hens housed in conventional cages. For other quality parameters (Karkulín, 2006 b) no significant differences were found among the cage systems except shell thickness and shell strength. Guesdon and Faure (2004) did not notice the influence of cage type on shell strength, and the mean value of this parameter amounted to about $35 \mathrm{~N}$ at 33 weeks of age. Nevertheless, in our study cages were one of the main factors affecting this parameter, and eggs from hens kept in furnished cages needed considerably greater strength to break the shell compared to the eggs from hens maintained in conventional cages.

Đjukić-Stojčić et al. (2012) reported higher Haugh units for eggs from hens kept in furnished compared to conventional or enlarged battery cages, but the difference was not statistically significant. A significant influence of cage type was demonstrated for shell thickness. In our study Haugh units were significantly influenced by all the main experimental factors (except $\mathrm{S}$ class eggs) and were higher for eggs from hens kept in furnished compared to conventional cages. All the changes found in smaller eggs were small and hard to confirm statistically.

Aydin (2006) reported that $\mathrm{pH}$ value changed by $4.46 \%$ in albumen and by $2.45 \%$ in yolk after 21 days of storage at room temperature. Samli et al. (2005) observed a rapid fall of albumen $\mathrm{pH}$ just after 2 days of storage regardless of temperature. They suggested that this parameter could be a useful tool for estimating changes in egg quality. Kokoszyński et al. (2008) also showed an increase in albumen alkalinity, indicating that in practice the height of albumen is the indicator of egg freshness. In our work, $\mathrm{pH}$ of both egg parts (albumen and yolk) remained significantly influenced by all the main experimental factors (cage type, storage time, egg weight) as well as by the $\mathrm{C} \times \mathrm{EW}$ and $\mathrm{EW} \times \mathrm{T}$ interactions in yolk and the $\mathrm{C} \times \mathrm{T}$ interaction in albumen.

It is concluded that eggs (especially those from the heavier weight classes, XL and L) from hens reared in furnished cages were characterised by considerably smaller quality changes (weight loss, yolk proportion, albumen height, Haugh units) due to storage time in relation to those from hens kept in conventional cages. This fact could indicate that they are more suitable for consumption. In addition to the housing system, changes occurring in eggs during storage should also be considered in terms of their weight class as an important factor affecting egg quality. Economically important egg traits (e.g. egg weight, shell strength) were better in eggs from furnished compared to conventional cages. 


\section{References}

Ay d in R. (2006). Effect of storage temperature on the quality of eggs from conjugated linoleic acid-fed laying hens. S. Afr. J. Anim. Sci., 36: 13-19.

Đjukić-S tojčić M., P erić L., Bjedov S., Milošević N. (2009). The quality of table eggs produced in different housing systems. Biotech. Anim. Husbandry, 25: 1103-1108.

Đjukić-Stojčić M., Perić L., Milošević N., Rodić V., Gla močić D., Škrbić Z., Lukić M. (2012). Effect of genotype and housing system on egg production, egg quality and welfare of laying hens. J. Food Agric. Environ., 10: 556-559.

F errante V., Lolli S., Vezzoli G., Cavalchin i L.G. (2009). Effects of two different rearing systems (organic and barn) on production performance, animal welfare traits and egg quality characteristics in laying hens. Italian J. Anim. Sci., 8: 165-174.

Gavril R., Usturoi M.G. (2011). Effects of temperature and storage time on hen eggs quality. Lucrări ştiinţifice; Seria Zootehnie, 56: 259-264.

Gues d on V., F a u r e J.M. (2004). Laying performance and egg quality in hens kept in standard or furnished cages. Anim. Res., 53: 45-57.

H e s t e r P.Y. (2005). Impact of science and management on the welfare of egg laying strains of hens. Poultry Sci., 84: 687-696.

J in Y.H., L e e K.T., L e e W.I., H a n Y.K. (2011). Effects of storage temperature and time on the quality of eggs from laying hens at peak production. Asian-Aust. J. Anim. Sci., 24: 279-284.

J on es D.R., Mus grove M.T. (2005). Effects of extended storage on egg quality factors. Poultry Sci., 84: 1774-1777.

K a rkulín D. (2006 a). Comparison of production and egg quality parameters of laying hens housed in conventional and enriched cages. Proc. EPC 2006 - 12th European Poultry Conference, Verona, Italy, 10-14.09.2006. World's Poultry Science Association (WPSA).

Karkulín D. (2006 b). Influence of two different cage technologies on the eggshell quality and the feather cover of laying hens. Ann. Fac. Eng. Hunedoara, 4: 218-222.

Kokoszyński D., Korytkowska H., B awej M. (2008). The effects of storage time of hen eggs under refrigeration conditions on their quality (in Polish). Pr. Kom. Nauk Rol. Biol., BTN, Seria B, 64: 31-37.

Kraw c z y k J. (2009). Effect of layer age and egg production level on changes in quality traits of eggs from hens of conservation breeds and commercial hybrids. Ann. Anim. Sci., 9: 185-193.

Menezes de P.C., Lima de E.R., Medeiros de J.P., Oliveira de W.N.K., Evêncio- N e to J. (2012). Egg quality of laying hens in different conditions of storage, ages and housing densities. R. Bras. Zootec., 41: 2064-2069.

P o hle K., Cheng H.W. (2009). Comparative effects of furnished and battery cages on egg production and physiological parameters in White Leghorn hens. Poultry Sci., 88: 2042-2051.

R o 11 V.F.B., B riz R.C., L e vrin o G.A.M. (2009). Floor versus cage rearing: effects on production, egg quality and physical condition of laying hens housed in furnished cages. Ciênc. Rural, 39: $1527-1532$.

S a fa a H.M., S e rr a no M.P., Va l e n c i a D.G., A r b e X., J i mén e z - M o r e no E., Lá z a ro R., M a t e o s G.G. (2008). Effects of the levels of methionine, linoleic acid, and added fat in the diet on productive performance and egg quality of brown laying hens in the late phase of production. Poultry Sci., 87: 1595-1602.

S a m li H.E., A g m a A., S e n k o y lu N. (2005). Effect of storage time and temperature on egg quality in old laying hens. J. Appl. Poultry Res., 14: 548-553.

S a r i c a M., O n d e r H., Ya m a k U.S. (2012). Determining the most effective variables for egg quality traits of five different hen genotypes. Int. J. Agric. Biol., 14: 235-240.

S c o t t T.A., S i l v e r s i d e s F.G. (2000). The effect of storage and strain of hen on egg quality. Poultry Sci., 79: 1725-1729.

Şe keroğlu A., S a ri c a M., D e mir E., Ulut aş Z., Tilki M., S a a t c 1 M. (2008). The effects of housing system and storage length on the quality of eggs produced by two lines of laying hens. Archiv. Geflügelk., 72: 106-109.

T a b i d i M.H. (2011). Impact of storage period and quality on composition of table egg. Adv. Environ. Biol., 5: 856-861. 
Tactacan G.B., Guenter W., Lewis N.J., Rodriguez-Lecompte J.C., House J.D. (2009). Performance and welfare of laying hens in conventional and enriched cages. Poultry Sci., 88: 698-707.

Trziszka T., Dobrzański Z., Ozi embłowski M., Jarmoluk A., Krasnowska G. (2004). An attempt to compare the quality of chicken eggs from cage system and ecological production. Archiv. Geflügelk., 68: 269-274.

T ům ová E., S kř i va n M., Engl m a i e rová M., Z i t a L. (2009). The effect of genotype, housing system and egg collection time on egg quality in egg type hens. Czech J. Anim. Sci., 54: 17-23.

Valkon en E., Venälä in en E., R o s s ow L., Va l a j a J. (2008). Effects of dietary energy content on the performance of laying hens in furnished and conventional cages. Poultry Sci., 87: 844-852.

Z i t a L., T ů m o vá E., Š to l c L. (2009). Effects of genotype, age and their interaction on egg quality in brown-egg laying hens. Acta Vet. Brno, 78: 85-91.

Received: 28 V 2013

Accepted: 20 I 2014 